\title{
Supply Chain Coordination and Performance Management with Real Options Based Relationships
}

\author{
Blake Johnson \\ Stanford University, USA
}

\begin{abstract}
A company's operating capabilities, performance and risk are determined by its supply chain, the complex set of activities spread across internal functions and external partners that together enable it to deliver its products. Supply chains have traditionally been coordinated with deterministic plans together with inventory buffers added to accommodate uncertainty. More recently, substantial investments have been made in supply chain information sharing, collaboration, and responsiveness initiatives to enable supply chains to react more rapidly to the outcomes of key sources of uncertainty as they become known. To date, however, capabilities that enable supply chain uncertainty to be identified and evaluated before the fact, and its performance impact proactively quantified and managed, have been absent, and as a result offer the potential for significant further improvements in performance and control. Implementation of such approaches is made difficult, however, by the complex, operational nature of supply chain activities, the multiple sources of uncertainty typically present, and the often competing or conflicting objectives and asymmetric information of the multiple firms or functions whose activities must be coordinated. To address these challenges a two part approach is present. The first addresses optimal management of individual firms or functions, while the second presents mechanisms for effective coordination between them.

Negotiated, bilateral, contingent performance commitments - effectively contracts with multiple embedded real options - are shown to be necessary to convey the information, incentives, and allocation of risk required to identify and execute appropriate strategies across the supply chain and across the range of prospective future supply and demand outcomes to which it is exposed.
\end{abstract}

Keywords: Supply chain, Performance management, Risk management, Flexibility

(Multinational Finance Journal, 2010, vol. 14, no. 3/4, pp. 153-188)

(C) Multinational Finance Society, a nonprofit corporation. All rights reserved. DOI: $10.17578 / 14-3 / 4-1$ 


\section{Introduction}

The field of supply chain management has evolved rapidly over its approximately 15 year history, from an initial focus on logistics and physical distribution to a scope that now encompasses "end-to-end" product delivery. Effective product delivery requires coordination across a wide range of activities from $R \& D$ to product design, capacity investment, procurement, manufacturing, distribution, sales, service and support. These activities are exposed to multiple sources of uncertainty, and in most supply chains, distributed across a broad network of firms and their internal functions.

This evolution in the scope of supply chain management, and the parallel rise in its strategic importance, has been driven by the value and competitive advantage that has been realized by firms which have succeeded in managing these complex and interrelated components of their product delivery processes more effectively than their competitors. Firms in industries as diverse as computing, retailing, automotive, semiconductors, and air travel, such as Dell, WalMart, Toyota, TSMC, and Southwest Airlines, have achieved levels of cost, asset utilization, market responsiveness, growth, profitability, and predictability of performance that have transformed their industries, and changed the basis of competition within them.

Because they address decision making under uncertainty, real options methods are well suited to enable competitive advantage in supply chain management. When used to structure relationships between the firms and functions of a supply chain, they can enable coordinated planning for key sources of uncertainty and efficient contingent response to their outcomes by enabling credible communication of information, alignment of incentives, and allocation of risk across parties. As described below, real options tools and insights are at work in many of the most important supply chain innovations of recent years. As also described, however, to date applications of real options in supply chain management have only begun to address their available potential, and many opportunities for significant extensions in their scale, scope and impact remain.

To realize this potential, however, a number of important challenges that result from unique features of the supply chain, both analytical and organizational, must be overcome. The most important of these are the operational complexity, and the day-to-day nature, of supply chain management activities, and the large number of people, decisions, and actions they encompass as a result. Second, and closely related, is the 
large numbers of independent firms and semi-independent internal functions across which these operational activities must be coordinated, each of which has its own information, objectives, capabilities and circumstances. The third key challenge is the non-commodity nature of the products and assets in question, from raw materials to capacity, production processes, sales and distribution resources, and the related absence of associated markets and traded instruments.

As described below, the complexity introduced by these features of the supply chain environment can be addressed through appropriate "disaggregation" of the management of the overall supply chain into subsets of activities of manageable scope, together with the use of real options-based methods to coordinate activity across, or manage the boundaries between, these subsets of activities. This approach, its analytic and organizational requirements, and the application areas and business impact of its practical implementations to date, are the focus of this paper.

The remainder of the paper is organized as follows. Section II provides context by summarizing the key activities of supply chain management, and the resulting opportunity for operations-level real options capabilities. This includes both planning and executing activities across the multiple firms and functions involved, and appropriately measuring, managing and attributing performance. Section III briefly describes the predominantly deterministic processes that supply chain management has historically relied on, their performance impact, and resulting opportunities for improvement. Section IV presents a general model for the management of a subset of the overall activities of a supply chain, for example the subset managed by an individual firm or function of the supply chain. Section VI presents an approach for coordinating activity across the overall supply chain through effective management across the "boundaries" between these independently managed subsets of activities. Section VII illustrates the application of the methods presented in sections IV and VI to key supply chain activities, including procurement and supply and demand matching. Section VIII briefly summarizes implementations of these methods at a number of leading companies, and offers conclusions.

\section{Primary Activities of Supply Chain Management}

Supply chains compete on the multiple dimensions of their product (or 
service) delivery capabilities of importance to their customers. The principal dimensions these capabilities are:

(1) Product features

(2) Cost

(3) Availability and lead time

(4) Ability to respond to customer requests, including customization, service, and support

(5) Liability and risk

The relative importance of each of these dimensions varies across products. For example, supply chains that deliver specialized design or technology-driven products generally compete on product features, availability, lead time, and customer responsiveness, while supply chains for commodity products place primary emphasis on cost and risk. The nature of a product's customer base, the market it is sold in, and its manufacturing and delivery requirements have similar effects.

A supply chain's performance on these dimensions of product delivery is determined both by 1) investments in resources made in advance across the supply chain, including product design, production capacity, supply of key materials, and infrastructure for distribution and sales, and 2) how these resources are utilized and coordination across them and the firms and functions that control them is managed over time and across potential outcomes of uncertainty. A stylized representation of these basic "physical" elements of a supply chain is shown schematically in figure 1 a for a simple, linear supply chain.

As shown in the figure, even for this simple, stylized supply chain resources span multiple firms, and within each firm span multiple functions, including design, procurement, manufacturing, distribution, marketing and sales. To plan and execute across this network of organizations efficiently, participating firms and functions must jointly identify the "physical" capabilities of the network and their associated "economics", including cost, value and risk. This is made difficult both by the complexity of the activities involved and by their distribution across multiple parties.

In reality, most actual supply chains are substantially more complex than the stylized supply chain of figure 1a, and are growing more so. Key drivers of this complexity include the increasingly international scope of operations in many industries, and the transition of industries from vertical to horizontal, both of which increase the scope and 
Domestic firm, vertical industry structure

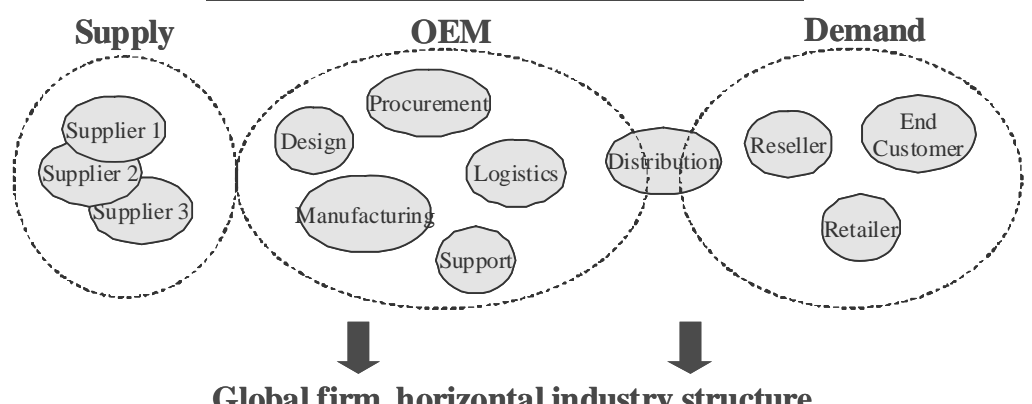

Global firm, horizontal industry structure

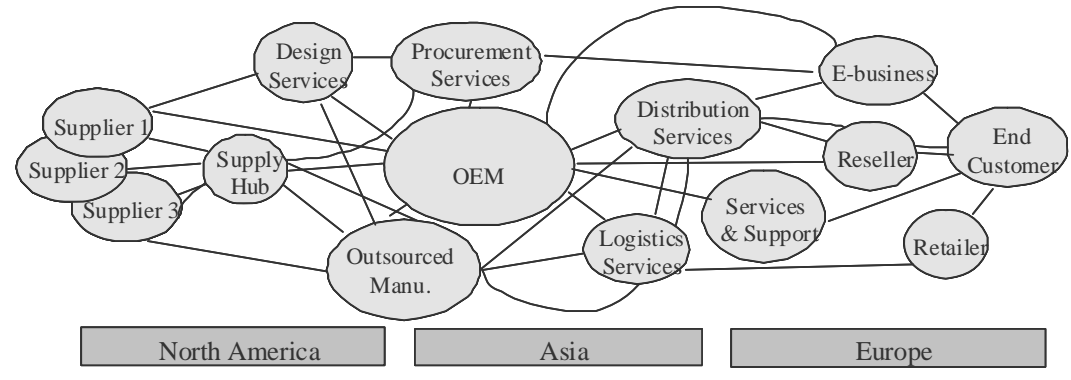

FIGURE 1.- Impact of globalization and trend toward horizontal industry structures on supply network complexity

number of participants in supply chains, as illustrated in figure $1 \mathrm{~b}$. To realize the potential value these changes in firm and industry structure enable, effective methods of coordination across the larger, more complex supply chain networks that accompany them are required. The predominantly deterministic methods of traditional supply chain management practices, as summarized briefly in the next section, are poorly suited to these requirements. This creates a need for methods that enable more effective identification of alternatives, alignment of incentives, and allocation of risk across parties.

\section{Traditional Supply Chain Management Approaches}

Supply chain management approaches have evolved with the scope of supply chain activities, from an initial focus on planning and cross functional coordination within individual firms toward planning and 
execution across the network of firms and internal functions that comprise today's supply chains.

The methods employed are based primarily on deterministic planning processes. These processes and their implications for resource investment, coordination, execution, and performance across the supply chain are summarized briefly below.

\section{A. Supply Chain Planning Systems}

Supply chain planning systems serve two purposes: to select resources and resource utilization policies to support a firm's plans, and to project the operational and financial performance the policies that are selected will generate. To date all commercially offered supply chain planning systems have been structured to calculate the resource investments and resource utilization policies that best meet a deterministic demand "plan", or forecast, and draw on deterministic optimization methods to do so.

In reality, however, numerous sources of uncertainty about both supply and demand are present in most supply chains. Because they are not acknowledged or incorporated in supply chain planning systems, supply chain performance is exposed to unidentified and unmanaged risks that result in performance "surprises" and execution challenges which are difficult to predict or control. Conflict between firms and functions often results as they struggle to coordinate their responses to unanticipated circumstances, and to meet requirements for which they may be poorly prepared and their incentives not aligned.

Firms and their internal functional groups are generally aware of the weaknesses of existing deterministic supply chain planning systems. However, the lack of alternative planning systems and the complexity of supply chain management activities leaves them with few operationally viable alternatives. For example, a common partial mitigation strategy is to run existing deterministic planning systems repeatedly, once for each of a set of "what-if" forecast scenarios. The result of this process, however, is a set of deterministic strategies, each of which is tailored to precisely meet a specific potential outcome of uncertainty, rather than a single, perhaps contingent strategy whose performance is robust to the range of possible outcomes. As a result, even as a group these plans and their associated performance projections provide little insight into the most appropriate strategy, or to the performance outcomes that any of the deterministic strategies identified 
might actually yield across the range of prospective outcomes.

In summary, traditional, deterministic supply chain planning systems leave supply chain managers unable to quantify, and therefore to proactively plan for and manage, the impact of uncertainty on their future operating and financial performance. Relationships between firms and functions built on this fragile, deterministic foundation lack the contingent performance requirements, incentives, and allocation of risk necessary to ensure effective management under uncertainty.

\section{B. Executing and Monitoring}

After the planning process is complete, firms execute the strategy that has been selected. In the ideal case, actual events match the "best guess" forecasts for supply and demand assumed in the plan. In most cases, however, sources of uncertainty not considered in "the plan" cause actual supply and demand to diverge from it. Since available supply chain resources and relationships have been tailored to the plan, they are rarely the best suited to these actual, divergent events. As a result, decisions and commitments must be revisited. However, the ability to do so effectively is constrained by the inflexibility and irreversibility common to supply chain commitments, and the complications created by the need to reach agreement with and coordinate action across the multiple firms and functions involved, each of which has its own objectives, information, and resources.

Performance measurement and accountability are difficult because initial goals and commitments fail to incorporate uncertainty, leaving responsibility for performance undefined when actual circumstances differ from planned.

\section{The Opportunity for Real Options-Based Approaches}

In contrast, if uncertainty is incorporated in the supply chain planning process, strategies with appropriate levels of flexibility and efficient allocations of risk and responsibility across parties can be determined. Like their deterministic counterparts, these strategies specify resource investment and utilization policies. Unlike deterministic strategies, they include "contingency plans", or real options and their exercise strategies and associated incentives, which ensure an appropriate and coordinated response across the supply chain to the range of events which may occur. By securing commitment to appropriate contingent performance 
across potential outcomes, future performance trade-offs and risks can be quantified and managed, and the accountability of individual firms and functions maintained across those outcomes.

For such a real options-based approach to be feasible in practice it must be able to accommodate the operational complexity and the large number of firms and functions of a typical supply chain. The next section presents an approach that makes this possible by "disaggregating" management of the overall supply chain into a set of sub-problems of manageable size. When combined with the methods presented in section VI for managing across the "boundaries" between these sub-problems, the desired overall result can be achieved.

\section{Model of the Management of an Arbitrary Subset of a Supply Chain's Activities}

This section presents a model of the management of an arbitrary subset of the activities of an overall supply chain. Key challenges include the presence of multiple sources of uncertainty and the operational complexity of the activities, and of the relationships and coordination with other firms and functions of the supply chain they require.

\section{A. State Space}

For simplicity of presentation, assume m types of goods exist, and that a finite, $n$-dimensional state space exists that represents the potential outcomes of the relevant sources of uncertainty over time. Let $X$ represent the set of $n x m$-dimensional state-dependent bundles of the $m$ goods, elements of which specify quantities of the $m$ goods in each of the $n$ states.

\section{B. Model of the Management of a Subset of a Supply Chain's Activities}

The management of a subset of a supply chain's activities is defined by:

(1) An objective function $V(x)$, for $x$ in $X$, which represents the objectives of the relevant management or stakeholders

(2) An endowment of resources or capabilities, which may include technological, physical and human capital 
(3) A transformation capability enabled by these available resources or capabilities and represented by the set $F_{p}$, comprised of the set of feasible input and output vector pairs $\left(x_{i}, x_{o}\right)$ for $x_{i}$ and $x_{o}$ in $X$.

(4) Sets of feasible exchanges with other firms and functions of the supply chain $x_{e}$, with one such set $F_{e} \mid\left(x_{i}, x_{o}\right)$ for each potential choice of input and output vectors $\left(x_{i}, x_{o}\right)$ in $F_{p}$.

By appropriate choice of $x_{i}, x_{o}$, and $x_{e}$, a firm or function may manage its initial endowment of resources or capabilities over time and across states.

\section{Optimal Management of the Subset of Activities}

Given this representation, the optimal management policy for the subset of supply chain activities solves:

$$
\begin{gathered}
\operatorname{Max} V\left(x_{i}+x_{o}+x_{e}\right) \\
\text { s.t. }\left(x_{i}, x_{o}\right) \text { in } F_{p}, x_{e} \text { in } F_{e} \mid\left(x_{i}, x_{o}\right)
\end{gathered}
$$

\section{Assessment of the Key Components of the Model}

\section{A. Transformation Capability Enabled by Resources and Capabilities}

The transformation capability of a specific set of supply chain activities may take a variety of forms, depending on the nature of the activities in question. For example, the capability may enable multiple inputs to be combined and transformed into one or more outputs (e.g. a manufacturing activity), the transportation, storage, and distribution of goods (e.g. logistics, distribution, or retail activities), or the identification of prospective counterparties and negotiation of terms of exchange for one or more goods (e.g. procurement and sales activities). Each of these activities is operationally complex, and its management requires detailed knowledge of available resources and capabilities, the feasible transformations they enable, and the associated feasible exchanges of relevant inputs and outputs. The following examples illustrate these characteristics: 


\section{Manufacturing Firm or Function}

Manufacturing firms or functions typically have complex transformational capabilities enabled by the technological capabilities, design, scale, and process capabilities of available capacity and the production alternatives it enables, as represented by feasible input and output pairs. In addition, performance on each of these dimensions may be uncertain, for example operating efficiency, processing time, production yield and quality, price and availability of inputs, and demand for and price of outputs. Further, many manufacturing activities also rely on proprietary manufacturing technology or process capabilities subject to on-going technological development. The task of a manufacturing manager is to understand, and to effectively utilize and evolve, the transformational capabilities these characteristics jointly define.

\section{Procurement or Sales Organization.}

In comparison, the transformational capabilities of a procurement or sales organization are typically comprised of skills and resources that support the design and negotiation of relationships, including acquisition and analysis of relevant information about market conditions, customer and supplier objectives and requirements, and competitor activities. Necessary skills include the ability to identify and assess the impact of relevant sources of uncertainty, including uncertainty about future market conditions, the relationship terms prospective counterparties will or will not agree to, and the likely actions of competitors. Top sales people and procurement managers often possess highly developed but quite intangible capabilities of this kind, which enable them to identify counterparties for and negotiate and execute transactions which others cannot.

While very different, these examples illustrate the important role that context-specific information, tacit knowledge, and multiple, operationally complex relationships play in the management of most supply chain activities. These characteristics of supply chain activities place high demands on management, which in turn limit the scope of activities that individual management teams can effectively address.

\section{B. Feasible Exchanges}

To realize value from their transformation capabilities, firms and 
functions must identify exchange counterparties and structure and negotiate terms of exchange that allow them to acquire sets of inputs and deliver sets of outputs that are feasible given their transformational capabilities and that generate acceptable levels of profit and risk. This process is made difficult by the lack of markets for most supply chain inputs and outputs, and more importantly by the range of complex "portfolio" effects that arise among exchange relationships, as described below:

\section{Absence of Markets}

The lack of markets for almost all supply chain goods limits their liquidity and the availability of information about potential counterparties and terms of exchange. As a result firms and functions must identify exchange counterparties and structure transactions using the often limited information available to them. Strategic considerations arise from asymmetric information, and the illiquidity of relationships generates path dependencies and complicates the management of positions over time as circumstances and objectives change.

\section{Portfolio Effects Between Input Acquisition Relationships}

Most supply chain activities require multiple inputs, for example the combination of raw materials and production capabilities required to produce a product. As a result, output is constrained by the "weakest link" in this "portfolio" of inputs, and dependencies arise among input acquisition relationships. In many cases "portfolio effects" are further complicated by the fact that one or more inputs may be substitutable. To optimize their input portfolios supply chain managers must therefore monitor the price and availability of all potentially relevant inputs, and dynamically optimize their input portfolio, subject to the capabilities and constraints of their transformation capabilities and the flexibility of their exchange relationships.

\section{Portfolio Effects Between Output Sale Relationships}

Firms and functions face an essentially identical challenge in managing their portfolios of output sale relationships, which typically include portfolios of both customers and of multiple outputs, or products. Like inputs, outputs are often substitutable or complementary, and demand 
across customers is often correlated.

“Asset-Liability Matching” of Input and Output Portfolios, Given Available Transformational Capabilities

The overall performance and risk of a firm or function is determined by the "asset-liability" match between the quantities and cost of its input portfolio and the revenue generated by its output portfolio, as enabled by its transformation capabilities. To manage its performance, a firm or function must therefore carefully coordinate the management of it portfolios of input and output relationships, bearing in mind its transformation capabilities.

The domain expertise and detailed operational management required to successfully meet these challenges places natural limits on the scope of supply chain activities that can be effectively addressed by an individual management team. In practice these limitation are visible in the distribution of the activities of a typical supply chain across multiple firms and internal functional groups. This distribution of activities across multiple organizational boundaries, however, makes effective methods for coordinating across such boundaries essential. Methods for doing this are the topic of the next section.

\section{Managing Across the Boundaries Between Firms and Functions of a Supply Chain}

To effectively manage supply chain activities that span the organizational boundaries of firms and internal functions, "portfolio effects" very similar to those within firms and functions considered above must be addressed.

For example, when an element of the input or output portfolio of an individual firm or function changes, because of portfolio interactions across its portfolio of relationships, the firm or function's objectives for and willingness and ability to perform across its other relationships will in general change also. These changes in turn impact the portfolios of each of its relationship counterparties. This triggers a similar sequence of events across these firms and functions and their relationship counterparties, and so on, with the ultimate result being a very broad scope of impact.

In the supply chain environment the triggering of broad portfolio 
effects by an initial small, localized change is not just a conceptual possibility. For example, if the availability of a single input, which may be economically inconsequential but physically required, is disrupted, all dependent activities across the supply chain will be affected, including procurement of other necessary inputs, and production, transportation, distribution, and sales of the product it is incorporated in. Changes of this kind in turn impact the activities of the associated suppliers, partners, and customers, and through them may impact a wide range of other firms and functions.

\section{A. Structuring and Management of Relationships Between Firms and Functions}

As portfolio effects that originate in one firm or function "ripple" across its immediate counterparties, and through the portfolios of these counterparties to each of their respective counterparties, each member of the network of affected firms and functions will seek to re-optimize its individual portfolio of activities in response, and the combined response across the network will define the response of the overall supply chain.

Consistent with the model of the optimal management of individual firms or functions presented in section IV above, each individual firm and function of the network will re-optimize its activities by adapting both its internal transformation activities and the structure and utilization of its portfolios of input and output relationships.

Since firms and functions possess full information about and control over their internal transformation activities, and the scope of these activities is by assumption manageable, each should be able to re-optimize their transformation activities effectively and on a timely basis.

In contrast, however, firms and functions often lack ready access to information about the feasible input and output relationships available to them given currently prevailing, and typically evolving, internal and external circumstances, for the following two primary reasons:

\section{Incomplete Information About the Identity and Transformational Capabilities of Prospective Counterparties}

Individual firms and functions are in general not aware of the identity and the specific transformational capabilities of their potential 
counterparties. First, as described above, these capabilities are generally complex and often only tacitly defined, making understanding of them by an "outsider" difficult and time consuming. Second, in many cases counterparties are likely to consider some or all of their capabilities confidential, and as a result may choose not to disclose them, even if doing so is feasible.

Incomplete information about the terms of exchange acceptable to prospective counterparties

The terms of exchange acceptable to a prospective counterparty depend on each of the elements of its portfolio management problem (as presented in section IV), including its performance objectives, the specific transformation activities it is currently executing and the other alternatives available to it, and its current and prospective sets of input and output relationships. Because these elements of a firm or function's portfolio management problem define its negotiating position and objectives, it is unlikely to be willing to disclose them. Further, since they also include information about the firm or function current and prospective relationships with other counterparties, the firm or function may in fact be prevented from disclosing them due to confidentiality restrictions or the potential for conflict of interest.

Given these informational constraints, firms and functions generally must structure and negotiate their input and output relationships with only minimal information about the objectives, circumstances, and capabilities of their prospective supply chain counterparties. The following proposition summarizes the implications of these informational constraints for the feasibility of prospective forms of supply chain relationships.

Proposition: Optimal relationships between firms and functions of a supply chain must take the form of enforceable commitments to observable performance, which may include contingent commitments defined on observable outcomes of uncertainty.

Proof: Relationships must be defined based on observable performance, since the alternative of defining them based on a counterparty's "inputs", "effort", "activities", or similar parameters would require each counterparty to have both the right and the ability to verify these parameters of the other counterparty. This is infeasible, both due to the complexity and to the proprietary nature of the information which would have to be shared between counterparties to 
Supply base core competence

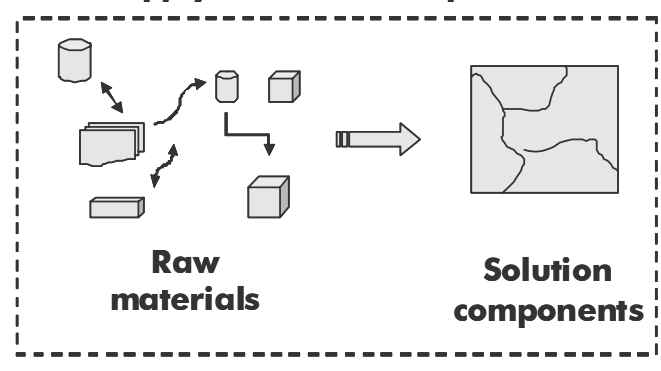

Customer requirement

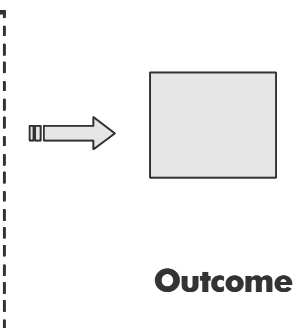

High

Low

Execution risk and complexity

Constraints placed on solution

FIGURE 2.- Impact of defining relationships using outcomes versus inputs

enable it. Second, performance must be committed, since relationships without commitment will either lack enforceability or will require the right to verify, or audit, activities undertaken to honor the committed performance. This is infeasible for the reasons listed above. (see figure 2)

\section{B. Process for Structuring Mutual Contingent Performance Commitments, or Real Options-Based Relationships}

One feasible process for determining appropriate terms for a specific contingent performance commitment (or real options-based relationship) without access to counterparty objectives, circumstances or capabilities, is simply to iteratively exchange and refine proposed terms until a set of terms acceptable to both parties is identified. The terms must define the specific commitments and optionality each party seeks (the "what"), and the reciprocal commitments, compensation, incentives, and allocation of risk it is willing to assume in exchange (the "why").

Figure 3 illustrates this process, beginning with a stylized representation of a buyer's uncertain demand. Together with information about the economic consequences to the buyer of having either too much or too little supply (inventory liability and backorders and lost sales, respectively), and the impact of price level and risk on its 


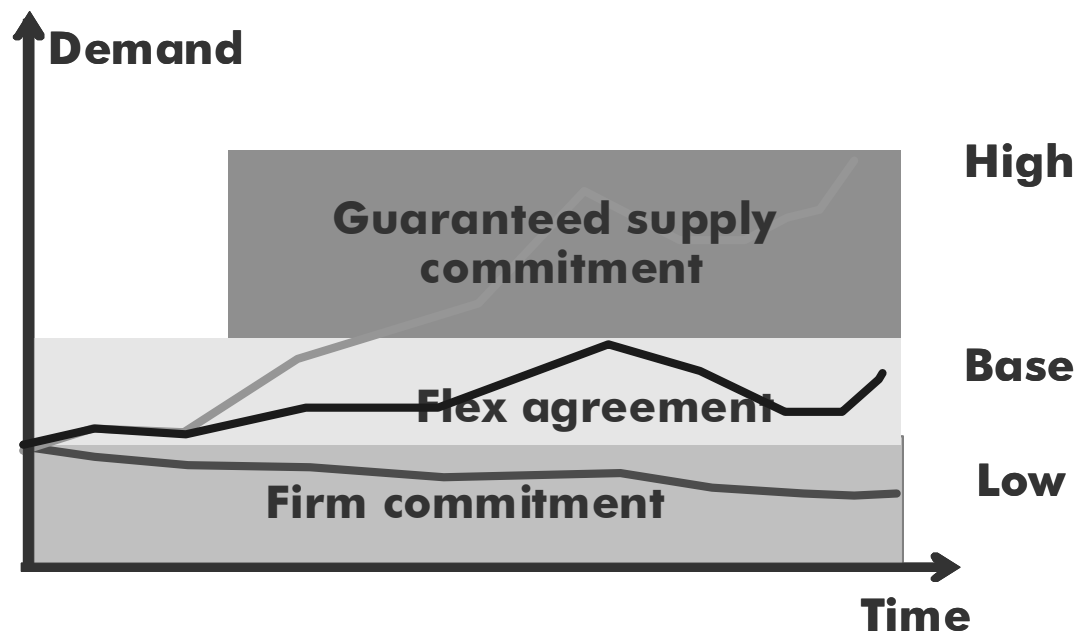

FIGURE 3.- Buyer's analysis to determine appropriate "tiered" request for supply pricing, flexibility, and lead time

cost and margin competitiveness and predictability, this information summarizes the role of the good in the buyer's overall portfolio.

Drawing on this information, together with whatever information the buyer may have about the prospective supplier's objectives, capabilities, costs, and risks, the buyer constructs terms for one or more contingent supply commitments that meet its business objectives while minimizing its estimate of the cost and risk the supplier must incur to honor the proposed commitment. A stylized version of a portfolio of supply commitments constructed to meet the demand scenarios in figure 3 is also shown in the figure. The portfolio is comprised of three supply contracts, each with terms for quantity, price and delivery lead time tailored to different "tiers" or "segments" of the buyer's demand distribution, as represented by its demand scenarios. Price performance can be contracted on in a similar way.

Specifically, the buyer reflects its high degree of confidence that its demand will at least equal the low demand scenario by offering to commit to purchases near that level. By assuming this level of demand risk over the planning horizon shown, the buyer enables the supplier to reduce cost through long lead time planning and production for this level of demand. In contrast, the buyer asks the supplier to assume the demand risk in the region of the high scenario by committing to provide 
supply up to that level - a supply option exercisable should demand at that level be realized - on committed terms for price and delivery lead time.

To support this commitment, the supplier may need to reserve capacity and ensure that it will be able to access necessary raw materials at prices and lead times that ensure its ability to perform, should they be required. To convince the supplier to agree to this commitment, the buyer may accordingly need to agree to share some or all of the costs and risks the supplier must incur to establish and maintain these contingent resources. Flexibility and risk sharing terms of this kind can be implemented with various forms of option structures, including sizing of the up-front option premium to allocate an appropriate share of the supplier's up-front costs to the buyer, and of the option exercise price to compensate the supplier for the remainder of the risk it assumes. Other key option parameters include the supplier's committed delivery lead time (or equivalently the buyer's option exercise lead time), which defines the portion of the supplier's overall production cost and risk it must incur prior to learning the buyer's actual exercise decision, and the size of the buyer's option request relative to the size of its fixed purchase commitment, increases in which increase the supplier's risk non-linearly.

Once the buyer has completed this analysis of its requirements and performance objectives, and of the relative ability of alternative sets of supply commitments to meet them, it asks the supplier to respond to the structures identified. To respond to the buyer's proposal the supplier completes a similar analysis of its objectives, product delivery capabilities, the other product delivery commitments it has already agreed to, and responds with pricing. If relevant, it may also provide information about the feasibility of its honoring the commitments the buyer has requested, and about alternative structures it believes may meet the buyer's requirements at lower cost or risk.

Once the supplier returns its responses, an iterative process of exchange, negotiation, and refinement of offers follows, as depicted in figure 4, until a mutually acceptable set of terms are agreed on. Depending on the circumstances, a single supplier may meet all of the buyer's requirements, or the buyer may establish a portfolio of such relationships with two or more suppliers.

\section{Convergence and Optimality of the Process}

Conceptually there is no reason why supply chain counterparties cannot 


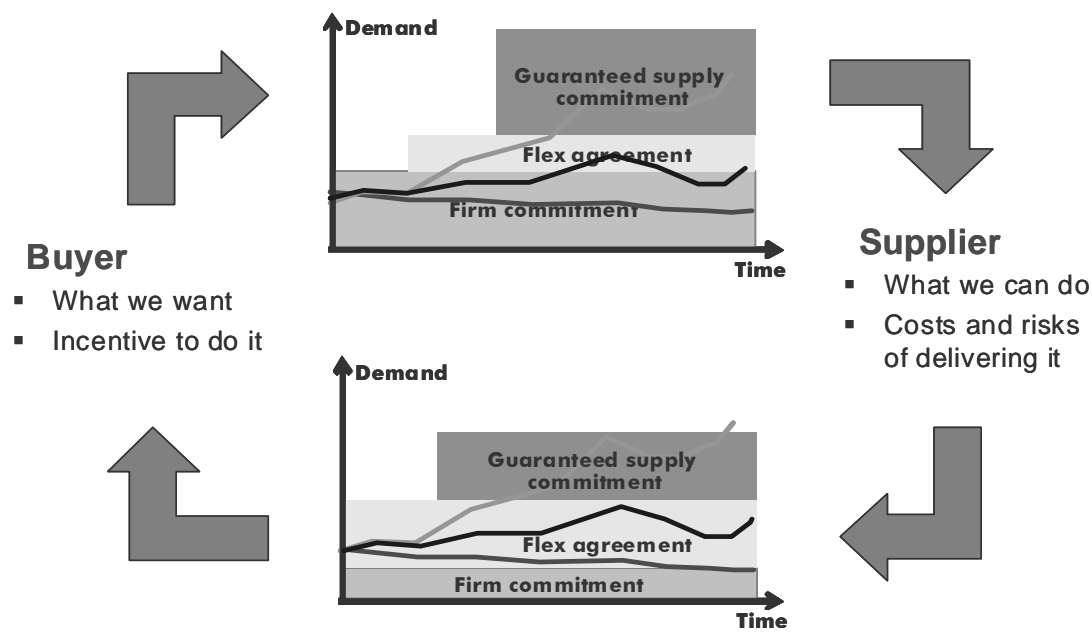

FIGURE 4.- Process of exchange and refinement of offers to identify mutually agreeable performance commitment

iteratively execute the steps described above, each time "probing" the set of feasible relationships, in an attempt to converge to the optimal portfolio of counterparties and relationships. The degree to which relationship counterparties may choose to exploit the full potential of this process is limited, however, by two important considerations about the revelation of strategic information. Each is described more fully below.

\section{"Probing” and Informational Revelation}

Repeated "probing" of the set of feasible relationships gradually reveals more information about the set of relationship terms that are acceptable to each counterparty, and therefore about their proprietary circumstances, objectives and capabilities. As a result, in addition to the standard cost-benefit trade-off of the decision to continue searching, firms or functions engaged in a process of iterative relationship structuring and negotiation of this kind will in general wish to limit the number and structure of prospective performance commitments they negotiate. By doing so they can balance the likely gains from further "probing" against the additional information about their acceptable performance commitment space this activity will reveal. 
"Specificity" and Information Revelation.

A similar trade-off exists between the incremental improvement in coordination that may be achieved and the value of the additional information likely to be revealed by performance commitments specified at increasing levels of specificity about the options, contingencies, and type and extent of flexibility and commitment agreed to between the counterparties. While greater granularity allows counterparties to coordinate performance more completely, it also reveals more detailed information about their individual preferences, capabilities, and requirements. For example, a buyer that seeks upside flexibility to meet potential demand from a prospective new customer, or from an as yet unannounced new product launch, may, in order to maintain the confidentiality of this information, request an "unconditional" supply availability commitment rather than a presumably more efficient and less expensive conditional commitment which may be exercised only if the relevant customer is signed or product launched.

Last, it is important to note that the relationship structuring process described above involved a single good and a small number of prospective counterparties. The "portfolio effects" that exist across a firm or function's overall portfolio of relationships and activities, however, create linkages between it and other inputs, outputs, and activities which must be taken into consideration to optimize its overall portfolio. Firms or functions may incorporate these interactions by negotiating relationships for closely linked inputs and outputs in parallel, and monitoring their broader portfolio interactions while doing so. For example, a manufacturing function may choose to negotiate purchase agreements for a product's key inputs in parallel with the negotiation of a major delivery commitment for the product. Doing so enables it to both manage its procurement cost and performance risk, and to utilize information about current input market conditions to guide its negotiation of terms for its product delivery commitment.

\section{Sample Application Areas}

\section{A. Procurement of a Good with Multiple Buyers and Suppliers}

There are a large number of goods for which multiple buyers and 
suppliers exist but for which markets do not, perhaps because the number of buyers and sellers is not large enough to support a market, or the good is not sufficiently standardized, or lacks the required economic significance. ${ }^{1}$

Suppliers of such goods generally sell to multiple buyers, which allows them to reduce risk and achieve economies of scale by pooling demand across customers. This ability to diversify the demand risk of individual buyers makes suppliers natural providers of demand risk management to buyers.

In contrast, buyers with access to multiple suppliers generally focus on managing price performance. If their demand is highly variable and capacity is expensive or subject to long lead times, they may also seek assured access to supply. Given these considerations, buyers generally focus relationship terms on price performance and allocation of price risk, for example through fixed price schedules, indexed-based pricing, and / or price caps and floors. When and where required, terms that specify guaranteed levels of supply availability are also included.

In addition to enabling price and availability risk to be managed, optimal portfolios of relationships between buyers and sellers also enable commitments and performance to be tailored to the specific circumstances and objectives of individual buyers and suppliers. Suppliers, for example, may differ in their scale, cost structure (e.g. fixed versus variable cost), production flexibility and lead time, current level of capacity utilization, capital structure, and geographic location, among other variables. Similarly, buyers may differ in the volume, duration, seasonality, variability, and geographic location of their demand, and the margin of and market objectives for the product in which they are incorporating the good in question.

Suppliers with a highly leveraged capital structure, for example, may

1. In recent years, significant attention has focused on the possibility of creating markets for goods that are not currently traded, but for which there appear to be enough buyers and sellers to support a market, if not for continuous trading, perhaps in "call" market form. In many such cases, however, would-be market-makers have found the presence of either or both a few large buyers or sellers makes establishing a market difficult, since the absence of a market enables large players to benefit from their superior information about available counterparties and their acceptable terms of trade, and about related conditions of and trends in overall supply and demand. Drawing on this informational advantage they can extract value through privately negotiated bilateral transactions with less informed parties that they would be unable to extract in a market environment, where the majority of this information would become publicly available. Prominent examples include DRAM, forest products, and electricity. 
prefer to sell through fixed purchase commitments, and may be willing to offer a price discount in exchange for the revenue commitment and the lower cost capital structure and reduction in risk it provides. Similarly, a firm with a low current level of capacity utilization may bid aggressively for contracts for committed purchase, while a supplier with a high current level of capacity utilization may seek higher margin sales, for example through flexible supply commitments.

Similarly, differences in supplier production flexibility and production lead times will in general lead to segmentation of suppliers based on flexibility and lead time. For example, buyers frequently employ various forms of "dual sourcing" strategies, under which one or more low cost, long lead time suppliers, perhaps in more distant geographic locations (e.g. China) are combined with one or more short lead time, higher cost suppliers to establish a portfolio of supply options tailored both to the buyer's overall level of demand volatility and to the lead time at which this volatility is resolved as demand information is received from customers. More generally, supply portfolios can be structured to leverage differences in the circumstances, capabilities, and objectives of individual suppliers to provide buyers with supply performance tailored to a broad range of prospective performance and risk management objectives.

In a similar way, suppliers can utilize differences in the objectives and key characteristics of buyers to tailor performance of their sales portfolios to their business objectives. For example, buyers with high profit margins or high levels of demand variability will naturally seek greater levels of assurance of supply and supply flexibility, respectively, than buyers with low margins or more predictable demand. Similarly, the terms of relationships that different buyers maintain with their customers will also affect the structure and terms of the supply relationships which they will seek. For example, buyers with fixed-price sales relationships are likely to wish to "asset-liability" match them against fixed-price supply relationships with similar volumes and duration. Similar but more complex opportunities exist for matching supply flexibility and lead time to sales volume flexibility and the lead times offered to customers. In the ideal, fully developed case firms dynamically manage both the "buy" and "sell" sides of their portfolios given their transformation capabilities and costs, and identify the "crossing" opportunities that create the most value and which most effectively manage risk across the supply chain over time. 
Example: Dell

The success of Dell's build-to-order, direct-to-consumer personal computer supply chain can be easily understood in this framework. Dell assembles personal computers from highly standardized components such as memory, hard drives, monitors and processors that are supplied by competing suppliers. These suppliers make expensive, long lead time $R \& D$ and capacity investments, and face long production cycle-times, for example 10 weeks or more for semiconductors. Prior to Dell, large PC manufacturers assembled these components into standardized products in large production runs designed to minimize manufacturing costs, and shipped them to distributors and retailers in bulk shipments designed to minimize distribution costs.

This long lead time, high volume product assembly and distribution process created an inflexible, long lead time supply chain poorly matched to the volatile demand and rapid rate of technological change of the PC market. As a result, PC manufacturers suffered lost revenue from missed market opportunities, and inventory write-downs from products poorly matched to demand.

Dell's build-to-order, direct-to consumer PC supply chain capitalized directly on these market opportunities and their underlying supply chain causes, resulting in improved customer satisfaction and more predictable profits. Rather than assembling standardized PCs in large volumes based on projections of market demand and component pricing and availability, Dell continuously monitored PC demand and component pricing and supply, and offered PC configurations matched to customer demand and built with available and competitively priced components directly to customers via telephone and the internet. Dell delayed the actual purchase of components until a customer placed an order for a specific configuration, and then purchased only those components, assembled the individual computer, and shipped it directly to the customer. In effect, Dell created an alternative "spot-to-spot" PC supply chain to capture the option value inherent in the volatility of short term supply and demand which had been left unexploited by the less flexible and responsive "forward-to-forward" supply chain of the remainder of the PC industry.

To execute this business model, Dell required transformational capabilities very different from those of its competitors. In contrast to high volume, low cost manufacturing and distribution, it required the ability to efficiently build and ship individual computers directly to end customers. In contrast to purchases of large volumes of fixed 
configurations of components from suppliers based on forecasted demand, it required the ability to locate, purchase, take delivery and assemble computers with a diverse set of components from a fluctuating set of suppliers. And in contrast to maintaining a small number of sales relationships with large distributors and retailers, it required the ability to attract and interact with end customers directly through the "virtual" channels of the telephone and internet, rather than through physical locations. This required Dell to build its customer base independently, and to make customers comfortable with buying computers they could not see or touch, and with receiving them after the delay required to complete their assembly and shipping.

The success of Dell's approach provides clear evidence that for desktop PCs the incremental option costs of build-to-order assembly and shipment of individual systems to individual customers is more than offset by the value of the options to reduce component costs (which represent over $85 \%$ of the cost of a PC) and to better meet market demand these option costs make possible. In addition, by dramatically reducing the cycle time between its purchases of components and its sales of computers to end customers, Dell dramatically reduced its working capital requirements (creating its now famous negative "cash-to-cash" cycle), and benefited from lower average component prices due to the rapid downward trend in component prices driven by technological advances.

Dell's growth and evolution over time, however, have required it to continue to evolve its supply chain model. For example, as Dell's scale has increased, so has its influence on the overall supply and demand balance in the PC industry. As a result, rather than exploiting temporary imbalances in component supply vs. system demand, it must now use its agility to adapt more quickly to broader fluctuations in market conditions for key categories of components. In effect, the volatility it benefited from earlier has now becomes at least semi-endogenous to its business, and has been reduced as a result. At the same time, the negative impact of this reduction in relative supply volatility has been at least partially offset by on-going improvements in the quality and completeness of the information about supply and demand trends which Dell has access to, and by its ability to influence market demand, both made possible by its increased size.

As a second example, Dell suffered performance problems when it originally began competing for PC supply contracts with large corporations and government entities. In contrast to individual customers, who sought the lowest cost, highest performance PC 
configuration available at any given point in time, large entities generally requested delivery of PCs with a fixed configuration, and at a fixed price schedule, over a period of six months or more in order to enable efficient network management. Dell found its opportunistic procurement processes poorly suited to support these contractual commitments, and in a number of cases was forced pay substantially more than it expected in order to source the specific components it had committed to supply. In late 1999 these problems were aggravated by overall constraints in component supply markets, against which Dell's opportunistic procurement approach provides little protection beyond the ability to rapidly adjust product offerings and their sales prices to reflect adverse market conditions. In October of that year, Dell announced a $\$ 470$ million dollar reduction in earnings, triggering a $13 \%$ one day drop in its stock price.

\section{Procurement of a Custom, Sole-Sourced Good}

The coordination and risk management requirements of custom, sole-sourced goods lie at the other end of the spectrum from those of the "near commodity" goods described above. Specifically, the existence of multiple buyers and sellers for near commodity goods generally ensures readily available supply and demand for the good. This makes price risk management the focus of relationship management for both buyers and sellers, and limits operational considerations to the geographic proximity of potential counterparties and its impact on cost and lead time.

In contrast, high performance relationships between the single buyer and the single supplier of a custom, sole-sourced good require detailed communication of 1) the characteristics of the buyer's demand distribution, and of its cost of shortages and excess supply, and 2) the costs, risks, and lead times of the supplier's production alternatives. Why each of these types of information are important, how they can be credibly communicated between parties by embedding appropriate options in relationships, and how this enables coordination across the supply chain are discussed in more detail below.

\section{A. Buyer Demand Requirements: Impact of Demand Distribution and Learning Over Time}

Figure 5 shows two sample distributions of demand over time. Both 


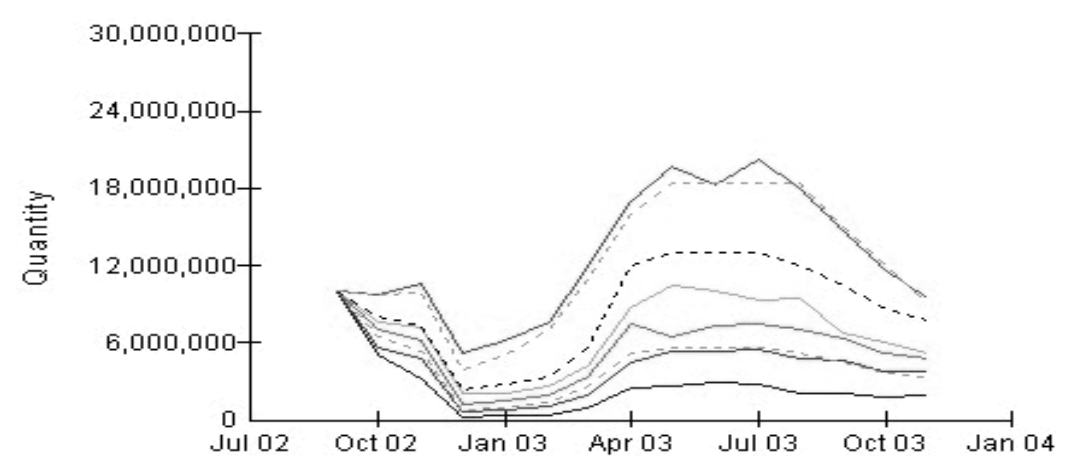

Distribution \#1

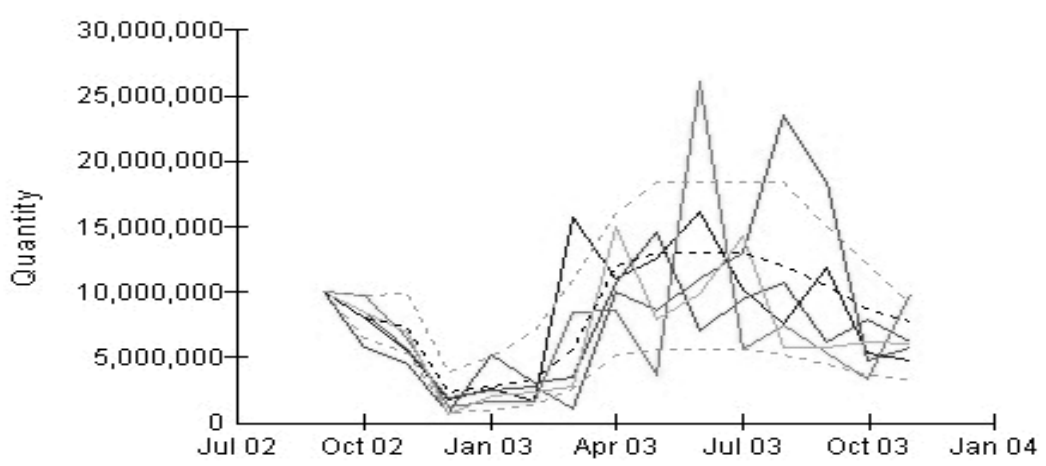

Distribution \#2

FIGURE 5.

distributions have the same unconditional distribution at each point in time, represented in the charts by the dotted lines, which show the $10^{\text {th }}$, $50^{\text {th }}$, and $90^{\text {th }}$ percentiles of these unconditional distributions over time. Both the expected level of demand and the degree of uncertainty about demand exhibit strong seasonality, and the level of uncertainty is roughly proportional to the level of demand. However, the volatility of demand over time, as reflected by the sample paths in the charts shown with solid lines, differs greatly between the two distributions, with the volatility in the first chart very low and in the second very high. For example, once early demand is observed under the first distribution, demand over the remainder of the roughly one year period shown can be forecasted with a high degree of accuracy. In contrast, under the 
second distribution very little "learning" over time is possible at any point during the forecast period. A review of the sample paths in this distribution reveals that demand frequently varies substantially from one month to the next, and in some cases fluctuates all from the lowest to the highest percentiles of the unconditional distributions over periods as short as three months.

These differences in the conditional distributions of the two distributions have important implications for supply chain planning. For example, while the first distribution might appear to be less costly and risky to supply, this is not necessarily the case. Specifically, although demand over time under the distribution is easy to accurately predict once early demand has been observed, because "high sample paths stay high" and "low sample paths stay low" over time, the distribution of cumulative demand over the forecast period is large. In contrast, the cyclical and volatile but broadly mean-reverting sample paths of the second distribution generate a much narrower distribution of cumulative demand. As a result, the decisions a supplier must make before early demand is observed, such as capacity investments, will be exposed to greater risk under the first distribution than the second. From a real options perspective, a premium will accordingly be placed on flexible, short lead time capacity strategies that allow at least a portion of required capacity investment to be delayed until after early demand is observed.

On the other hand, supply decisions that impact short term performance will be more difficult to make under the second distribution, due to its high short term volatility. To make these decisions well, all key parameters must carefully considered, including the costs and lead times of raw materials and production, and the costs of shortages and of holding and obsolescence of finished goods inventory.

For example, if lead times are short and the costs and risks of finished goods inventory are high, highly responsive production matched to current levels of demand may be optimal. In contrast, if lead times are long and the costs and risks of finished good inventory are low, relatively stable production may be optimal when combined with large inventories of finished goods to accommodate fluctuations in demand. The following examples illustrate these trade-offs, and how they can be identified and managed with appropriately structured options-based relationships between buyers and suppliers. 


\section{Example: Lead Time Optimization}

To optimize the lead time of its purchase options in a supply relationship, a buyer may begin by analyzing the conditional and unconditional distributions of its demand distribution to assess both the uncertainty of its demand and the timing and extent of its learning about that uncertainty over time. For example, analysis of the first distribution in figure 5 reveals that the buyer faces substantial demand uncertainty before observing its initial demand, but after learning about this demand faces very little subsequent uncertainty. Based on this analysis, the buyer may ask the supplier to commit to a high level of capacity flexibility to ensure that it will be able to accommodate the buyer's high level of "pre-launch" uncertainty about cumulative demand, but offer to accept a substantial delivery lead time to thereafter to fully utilize the high quality conditional demand information that becomes available shortly after product launch. To manage its exposure to demand uncertainty during the first period of the forecast given access to only long lead time supply, the buyer can establish an appropriately sized initial inventory buffer with confidence that, given the information contained in its unconditional distribution of demand over time, even if demand turns out to be low this initial inventory will be "burned off" over the duration of the product lifecycle.

From the supplier's perspective, the structure of this supply request clearly communicates the buyer's desire for long rather than short lead time supply flexibility, while its specific parameters communicate the level of flexibility required and the acceptable lead time. The structure and terms of the supplier's response will reflect the costs and risks it must incur to provide this flexibility. For example, given the long supply lead time requested it may be able to utilize contingent or "staged" investments in capacity or raw materials to reduce cost and risk.

In contrast, a buyer with the second demand distribution faces substantial on-going uncertainty at a one month lead time, and its conditional distributions for demand two or three months ahead provide little information beyond that included in its unconditional distribution. To manage these characteristics of its demand uncertainty the buyer may request substantial flexibility with a one month lead time, and sufficient additional options on supply with two or three month lead times to yield the required overall flexibility.

In response the supplier will first communicate whether it is able to 
honor the high level of flexibility and short delivery lead time requested, and if so the cost and risk of the resource commitments it must make to ensure it is able to do so. If the lead times of these resource commitments differ from the order lead times requested by the buyer, the supplier may request alternative order lead times to ensure it that its commitments are based on the best information available to the buyer at that time.

If the supplier is either unable to provide the requested flexibility at the lead times requested by the buyer, or if the costs and risks it must incur to do so exceed the value to the buyer, the buyer will be forced to adapt accordingly. For example, it may extend its delivery lead time to its customers, or offer them multiple lead times with pricing matched to their respective cost of supply.

In summary, relative to a "near-commodity" supply chain, the buyer and supplier of a custom, sole-sourced good must coordinate much more closely on developing and exercising real options tailored to their respective capabilities and requirements. It is this "individually matched" nature of the resulting relationship that guides the design and execution of the underlying physical supply chain. In contrast, in near-commodity supply chains, firms treat the activities and requirements of counterparty firms as largely exogenous. To meet their requirements they construct portfolios based on diversity in the types of relationships these counterparties seek, a process much more analogous to the construction of a financial portfolio to meet desired performance objectives.

Example: "End of Life” Supply

As a product or component nears the end of its lifecycle, risk increases, since excess inventory and capacity are increasingly exposed to obsolescence and salvage rather than merely holding costs. Demand uncertainty also frequently increases, as the level of final demand and the precise timing of product retirement vary in response to uncertainty about the timing, market acceptance, and availability of supply of a replacement product.

In response to this increase in risk, suppliers of custom products often require buyers to assume greater responsibility for demand uncertainty for a product as it nears end of life. For example, a supplier may require a buyer to either commit to a rate of purchases sufficient to ensure acceptable on-going utilization of the supplier's capacity and raw 
materials for the product, or to make a "last time buy" which allows the supplier to shut down production, clear raw material and finished goods inventories, and redirect associated resources. For the buyer, the ability to keep production open provides access to an on-going source of supply and "pay as you go" risk exposure, in contrast to the "pay up-front" risk and fixed quantity of a last time buy. To optimally combine these two options the buyer can evaluate them as components of a compound option. Under optimal exercise, the buyer will maintain a sufficient purchase commitment to keep production open until the distribution and timing of its remaining demand reaches a level which is more effectively served by an optimally sized last time buy.

\section{Example: "Swing" Contracts}

"Swing" contracts obligate a buyer to a level of cumulative purchases over time which lie in an interval between contractually specified minimum and maximum quantities. Swing contracts also typically specify minimum and maximum "take rates" during each period of the time interval which constrain the rate and timing of the buyer's purchases. These "take-rate" constraints are generally less restrictive, however, than the minimum and maximum flex ranges for each period which the same supplier would find acceptable without the cumulative purchase constraint, which limits the supplier's exposure to the variability of the buyer's cumulative demand.

The relatively complex option features of swing contracts and their impact on the allocation of risk between buyer and supplier are well suited to circumstances in which the buyer's demand is variable but exhibits mean reversion over time, and in which the supplier's production requires larger or longer term resource commitments, or its cost or performance can be improved by utilizing them. Swing contract parameters for minimum and maximum take rates and minimum and maximum cumulative purchases provide buyers and suppliers with the contract variables necessary to communicate and contract on these determinants of cost, value and risk. Through negotiation of these terms, appropriate operating boundaries and allocation of cost, value and risk can be established, enabling effective coordination between parties.

Example: Dell

In recent years Dell's product line has expanded to include a range of 
consumer products, such as personal digital assistants, flat panel TVs, and MP3 players. In contrast to PC's, these products are differentiated by both technical and design features which require customized components.

To effectively procure these customized components, close coordination and sharing of risk with suppliers is required, as described above. However, because opportunistic procurement of multi-sourced components has been a primary driver of Dell's success in the dominant computer segment of its business, close coordination and sharing of risk with suppliers requires significant process development and change management at Dell and in its relationships with suppliers. Because Dell's build-to-order, direct to consumer sales model and highly developed methods for the procurement of near-commodity materials have played a central role in Dell's differentiation and success, a number of analysts and other observers have questioned whether diverting from this model, and the categories of products well supported by it, is a prudent business decision given its potentially disruptive effect on Dell's core business processes, internal culture, and external relationships.

Example: Dynamic Optimization of Operating Boundaries, Including Quantity and Lead Time

Perhaps the most intuitive way to think about the optimal structuring and execution of real options in one-to-one buyer-supplier relationships is as a two stage process. In the first stage, the decisions and commitments available to the supplier to create, keep open, and manage the exercise of alternative supply options are identified and analyzed. In the second stage, appropriately structured relationships with the buyer are used to communicate the main physical and economic characteristics of these options, including key commitment points and their consequences for performance, and the buyer selects and exercises the subset of these options best suited to its requirements and performance objectives. This process is repeated over time, with the supplier updating its menu of production options as its circumstances, objectives, and resources, including its relationships with its suppliers and other customers, evolve over time, and the buyer updating its selection and utilization of these evolving options as its objectives and demand conditions evolve.

Two simple examples of this process that have had substantial 
impact on the practice of supply chain management in recent years are build-to-order manufacturing, and postponement strategies in production and distribution. Under build-to-order manufacturing, suppliers wait until a customer requests a specific product, and then build precisely that product. This enables all production commitments to be delayed until demand is known with certainty, eliminating all risk of unnecessary production activities, and of supply-demand mismatches. The nature of the build-to-order approach imposes important constraints, however, most notably that the buyer must be willing to accept an order lead time equal to the supplier's lead time of procurement and production, and that customized production of individual products be feasible and cost-competitive. For modular products that are simple to assemble, such as the PC's assembled by Dell, these conditions are satisfied. They clearly do not hold, however, for many other products that require complex or long lead time procurement, production or distribution, or which benefit from economies of scale in these activities.

Postponement strategies can be viewed as a generalization of build-to-order manufacturing. Under postponement, the production tasks that define the product attributes subject to the lowest level of demand uncertainty are completed in advance, and the tasks that define the product attributes subject to higher levels of uncertainty are delayed until better information about demand becomes available over time. As a result, production is not completed at a single point in time, nor is it typically completed in a single location. For example, advance "pre-production" may first be completed in bulk at a central location. Next, partially complete products are sent to a set of distributed locations close to end markets, where final production is completed once better information about actual demand in that region becomes available.

Two now classic examples of postponement are Hewlett Packard's bulk production of printers, under which manufacturing is completed centrally in bulk except for power suppliers, manuals, and other product features and packaging specific to regional and local markets, and Benetton's bulk manufacturing of sweaters in a single, neutral color, followed by dyeing to specific colors as demand information for specific colors arrives over time.

From an options perspective, as its name suggests, postponement enables a supplier to delay commitment to the product features exposed to the greatest demand uncertainty, while still realizing production and 
cost efficiencies in the production steps that define product features subject to lower demand uncertainty. As a result, to optimize postponement strategy a detailed analysis must be conducted of the level of demand uncertainty for specific product features, and of the cost and lead time of production and distribution options that enable commitment to product features subject to the greatest uncertainty to be delayed.

\section{Implications for Performance Analysis}

Replacement of existing, largely deterministic supply chain planning processes with methods of the kind described above which allow uncertainty to be proactively managed has a number of important implications for performance management, evaluation, and attribution.

\section{A. Performance Management}

The ability to explicitly quantify and manage the impact of uncertainty on future supply chain performance, whether that uncertainty originates from uncertainty about the performance of resources and capabilities internal to a firm or function or from its relationships with its supply chain partners, enables managers to better define and achieve performance objectives and trade-offs. Because this management capability applies at the operational level within firms and functions, these benefits can be realized at the level of individual product lines, business units, or functional activities, as well as at higher levels in a firm.

For example, firms typically seek to match their cost structure, product availability, lead time, and inventory exposure, and other key supply chain performance metrics to the specific circumstances and objectives of individual products and markets, such as product margin, stage in product lifecycle, customer product selection criteria and performance objectives, relevant supply market conditions, and actions of competitors.

Today, managers must communicate their objectives for performance on each of these dimensions and assess alternatives for achieving them on a predominantly qualitative basis, both within a firm and across its supply chain. Lacking the ability to quantify the performance implications of key sources of uncertainty, it is difficult for 
operational managers to align incentives and allocate risk across parties to effectively coordinate actions, and to hold parties accountable. This inability to quantify and manage performance uncertainty is even more problematic for more senior managers in a firm at the business unit, division, or firm level, since the performance impact of qualitative approaches to uncertainty management which may have been implemented at the operational level cannot be effectively aggregated and communicated.

In contrast, the ability to quantify product-level objectives and alternatives and to align supply chain counterparties to execute to them makes future performance across prospective outcomes of uncertainty visible to and controllable by management at each level in a firm, from product managers to the heads of the business units or divisions of which they are part, to the CFO and CEO. At each level, management is able to quantify and manage the risk exposures central to the firm's business, including its operational, customer, supplier, and market risks.

\section{B. Performance Evaluation and Attribution}

The ability to quantify and manage the impact of supply chain uncertainty on performance at all levels within a firm, and on its key supply chain relationships, has equally important implications for defining performance objectives and incentives, and evaluating and attributing performance outcomes.

Specifically, under previous deterministic supply chain planning and coordination processes, performance objectives, both within and between firms and functions, were by necessity based on "best guess" deterministic plans. When actual events diverged from plan, it was unclear who should "do what and get what", and therefore be held accountable for what, since such contingent possibilities, their consequences, and the appropriate response across the supply chain had not been discussed or committed. Because of the operational complexity of the activities involved, repeated re-planning, renegotiation of accountability, and setting of new performance expectations was required, which placed large demand on both management and operational staff.

In contrast, when supply chain performance across the range of prospective supply and demand outcomes is quantified in advance, "who will do what and get what" across these prospective events agreed, and appropriate incentives and performance metrics put in place, 
alignment and accountability are assured. As a result, performance evaluation and attribution across outcomes is straightforward and unambiguous, both within and across firms.

\section{Practical Applications}

A range of leading firms are actively applying methods for proactively managing supply chain uncertainty of this kind, both within their firms and across their supply chains. Dell, as perhaps the most well known, continues to evolve its business model and supply chain activities in an attempt to accommodate the increasing scope of its activities and breadth of its product line, as described above (see for example Johnson 2005). Agilent Technologies' innovative supply management processes represent perhaps the most fully developed and implemented processes of the kind described here (VanDam, 2004, Johnson 2002). Other examples include Ford's work to jointly optimize its capacity flexibility, supply flexibility, and component commonality (Everson and Johnson, 2004), Intel's option-based capital equipment procurement strategies (Vaidyanathan, Metcalf and Martin, 2005) and its contingency-planning or "playbook" approach for managing product transitions (Hopman, 2005). Further examples include the innovative combination of customer-responsive product design and short lead time supply of Spanish retailer Zara, Sony's optimization of its supply chains for specific product lines to their respective product lifecycles and to technological innovations in the key components that drive them (Jiang, 2003), Mattel's combination of "portfolio management" of internal and external manufacturing capabilities and "rolling-mix" product design and merchandising strategies for managing product availability and demand (Johnson, 1998, 2001), and GM's experimentation with integration of the management of product design and engineering with the availability and utilization of capacity for assembly and key components (Vlasic, 2004).

\section{Conclusions}

This article has presented a two step methodology for incorporating uncertainty into core supply chain planning, execution, and performance management activities. In the first step the problem of managing the 
overall supply chain is decomposed into small enough sub-problems to allow the operational complexity, and private information and control that typically accompanies it, to be effectively addressed. In the second step, effective coordination across the boundaries between these sub-problems is achieved with real-options based relationships. These relationships define contingent performance commitments which credibly communicate the information and which establish the incentives and risk sharing required to appropriately align and inform the parties. The approach was then applied to a range of one-to-one and many-to-many relationships, across supply chains with different underlying physical and economic characteristics and exposed to different forms of uncertainty. Finally, select examples of the practical implementation of the approach were described. While implementation of the approach requires changes to core management processes, leading companies are increasingly acknowledging the value and need of making such changes to function effectively in the increasingly uncertain and dynamic business environment.

Accepted by: Prof. L. Trigeorgis, Guest Editor, April 2007

Prof. P. Theodossiou, Editor-in-Chief, April 2007

\section{References}

Billington, C.; Johnson, B.; and Triantis, A. 2003. A real options perspective on supply chain management in high technology, Journal of Applied Corporate Finance, Winter.

Cachon, G. 2003. Supply chain coordination with contracts, Handbooks in Operations Research and Management Science: Supply Chain Management. Steve Graves and Ton de Kok, editors, North Holland.

Everson, M., and Johnson, B. 2004. Manufacturing Flexibility at Ford Motor Company, Parallax View.

Hopman, J., Managing uncertainty in planning and forecasting, Intel Technology Journal, Vol. 9, Issue 3, pp. 175-183.

Jiang, B. 2003. What pulled Sony out of China, Supply Chain Management Review, pp. 22-27.

Johnson, B. 2002. Quantifying and Managing Supply Risk and Flexibility at Agilent Technologies, Stanford University.

Johnson, B. 2005. Deconstructing Dell, Stanford University.

Johnson, B. 2005. Optimizing Tool Availability and Lead Time with Procurement Options, Proceedings of the Thirteenth Annual International Symposium on Semiconductor Manufacturing, San Jose, California.

Johnson, E. 1998. Mattel, Inc: Vendor Operations in Asia, Owen at Vanderbilt 
case study.

Johnson, E. 2001. Learning from toys: Lessons in managing supply chain risk from the toy industry, California Management Review, Vol. 43, No. 3, pp. 106-124.

Vaidyanathan, V.; Metcalf, D.; and Martin, D. Using Capacity Options to Better Enable Our Factory Ramps, Intel Technology Journal, Vol. 9, Issue 3, pp. 185-191.

Van Dam, C. 2004. Supply risk and flexibility management at Agilent, Parallax View.

Vlasic, B. 2004. Global SUV fuels GM's 'Revolution', Detroit News. 